DR. CRAIG LAMMERT (Orcid ID : 0000-0003-3809-640X)

Article type : Original Articles

\title{
Black Adult Patients with Acute Liver Failure are Sicker and \\ More Likely to Undergo \\ Liver Transplantation Than White Patients
}

\begin{abstract}
Lauren Nephew MD MSCE ${ }^{1}$, Zahra Zia MD ${ }^{2}$, Marwan Ghabril MD ${ }^{1}$, Eric Orman MD ${ }^{1,}$ Craig Lammert MD ${ }^{1}$, Naga Chalasani MD ${ }^{1}$
\end{abstract}

1. Division of Gastroenterology/Hepatology, Department of Medicine, Indiana University School of Medicine, Indianapolis, IN, United States.

2. Department of Medicine, Indiana University School of Medicine, Indianapolis, IN, United States.

Key words: Race, disparities, Hispanic, Asian, Stauts-1

This is the author's manuscript of the article published in final edited form as:

Nephew, L., Zia, Z., Ghabril, M., Orman, E., Lammert, C., \& Chalasani, N. (2019). Black Adult Patients with Acute Liver Failure are Sicker and More Likely to Undergo Liver Transplantation Than White Patients. Liver Transplantation, 0 (ja). https://doi.org/10.1002/It.25594 


\title{
Abbreviations:
}

ALF: Acute liver failure

AlH: Autoimmune liver disease

HE: Hepatic encephalopathy

HR: Hazard ratio

INR: International normalized ratio

LT: Liver transplantation

MELD: Model for end state liver disease

STAR: Standard Transplant Analysis and Research

UNOS : United Network of Organ Sharing

US: United States

\author{
Corresponding author \\ Lauren D. Nephew, MD MSCE \\ Assistant Professor of Medicine \\ Division of Gastroenterology and Hepatology \\ Indiana University School of Medicine \\ 707 Rotary Building, Suite 225 \\ Indianapolis, IN 46202 \\ Inephew@iu.edu \\ Phone: 617-510-1890
}

This article is protected by copyright. All rights reserved. 
Conflict of Interest: The authors have no conflicts of interest

Grant Support: This publication was made possible with partial support from KL2TR002530 and UL1TR002529

\section{Abstract}

Background: Racial and ethnic differences in the presentation and outcomes of patients waitlisted with acute liver failure (ALF) have not been explored.

Methods: Adult patients waitlisted for liver transplantation (LT) from 2002-2016 with ALF were investigated using the United Network of Organ Sharing database. Clinical characteristics and causative etiologies were compared between white, black, Hispanic, and Asian patients with ALF who were waitlisted Status-1. A competing risk analysis was used to explore differences in LT and waitlist removal. Kaplan-Meier survival curves were used to explore differences in 1-year post transplant survival.

Results: There were 8,208 patients waitlisted with a primary diagnosis of ALF; 4,501 were waitlisted Status- 1 (55.3\% of whites, $64.4 \%$ of blacks, $51.6 \%$ of Hispanics, $40.7 \%$ of Asians, $\mathrm{p}<0.001$ ). Black patients had higher bilirubin, INR, and MELD at waitlisting than other groups. White patients were the most likely to have acetaminophen toxicity as a causative etiology, while black patients were the most likely to have autoimmune liver disease. Black patients were significantly more likely to undergo LT than white patients $(\mathrm{HR} 1.20 ; 95 \% \mathrm{Cl}$ 1.30-1.86). There was no difference in waitlist removal because of death or clinical deterioration among racial/ethnic groups. One year post transplant survival was lowest in black patients (79.6\% blacks vs $82.8 \%$ whites, $83.9 \%$ Hispanics, $89.3 \%$ Asians, $p=0.02$ ).

Conclusions: Etiologies of ALF vary by race and ethnicity. Black patients with ALF were more likely to be waitlisted Status-1 and undergo LT than white patients, but were sicker at presentation. One-year post transplant survival was lowest amongst black patients.

This article is protected by copyright. All rights reserved. 


\section{Introduction}

Acute liver failure (ALF) is a rare but life threatening illness that results in hepatic dysfunction, coagulopathy, encephalopathy, complicated in $30 \%$ of cases by death ${ }^{1,2}$. While approximately $45 \%$ of patients with ALF will recover with supportive care, $25 \%$ will require liver transplantation $(\mathrm{LT})^{3}$.

Racial and ethnic disparities in treatment of chronic liver disease and its sequelae have been described, with ethnic and racial minorities being less likely to receive transhepatic portosystemic shunts, timely esophgogastrodudenoscopy for variceal hemorrhage, or direct acting antiretroviral agents for hepatitis $C^{4-6}$. There were racial disparities in LT for chronic liver disease in the past that have improved with adoption the model for end stage liver disease score (MELD) $)^{7,8}$. The ALF Study Group found no difference in mortality or LT between black and white patients with ALF; however the number of black patients was relatively small and the cohort begin enrolling in 1998, prior to the MELD era ${ }^{2}$. Less is known about racial or ethnic differences in the access to $L T$ in this group in the modern era.

The criteria for Status-1 waitlisting are strict and require a life expectancy of less than 7 days without LT and fulminant liver failure without pre-existing liver disease, or hepatic artery thrombosis within 7 days of transplant, primary non-function of a previous hepatic allograft, or acute decompensated Wilsons Disease ${ }^{9}$. The decision to apply for Status- 1 waitlisting is based on the clinician's judgement about a patients clinical course and likelihood of recovery without transplant. In light of this, it is important that clinicians understand the clinical presentations and outcomes of a diverse group of patients with ALF in order to make informed decisions about the need for LT. It is also important that we explore in racial and ethnic differences in access to transplant services. The goal of this study was to explore differences in the presentations, causative etiologies, and outcomes

This article is protected by copyright. All rights reserved. 
between racial and ethnic minorities waitlisted Status-1 with ALF for LT in the United States (U.S.).

\section{Methods}

\section{Study Population}

A retrospective cohort study of adult (18 years and older) patients waitlisted for LT in the U.S. with a diagnosis of ALF between February 27, 2002 and December 31, 2016 was conducted. The United Network of Organ Sharing (UNOS) maintains the Standard Transplant Analysis and Research (STAR) database which includes data on all candidates waitlisted for $L T$, including information regarding their diagnosis.

To determine the number of patients with ALF who required Status- 1 waitlisting all patients with ALF were first identified. ALF was defined by a primary diagnosis code of ALF or an unknown primary diagnosis code coupled with Status-1 waitlisting and a free text diagnosis code consistent with ALF. Because we were interested in characterizing and exploring outcomes in the most acute cases of ALF, further analysis was restricted to ALF patients waitlisted Status-1 for LT. Since Status-1 waitlisting requires strict criteria be met, this ensured that the cohort contained true ALF cases and was less likely to include acute on chronic liver failure patients or other misclassifications. Retransplant patients including some primary non-function cases were included in the primary analysis if they were waitlisted with a primary diagnosis of ALF and status-1.

This article is protected by copyright. All rights reserved. 
Race or ethnicity was categorized as white, black, Hispanic, and Asian based on UNOS classification. Patients coded as American Indian, Alaskan Native, Hawaiian/Pacific Islander, multiracial, and other were excluded due to small sample size. UNOS provides a race/ethnicity category labeled " ETHCAT" which classifies patients as white, black, Hispanic, or Asian, and also provides a category labeled "ETHN" which labels patients as non-Hispanic white or Hispanic/Latino. There were no patients labeled "ETHCAT" black but "ETHN" Hispanic.

Clinical characteristics and demographics including age, gender, body mass index, history of diabetes, blood type, laboratory MELD score and its components at the time of waitlisting, grade of hepatic encephalopathy, ventilator status at time of waitlisting, the need for dialysis in the week prior to waitlisting, and region were compared between groups. Causative etiologies were divided into 7 categories including: 1) drug induced liver injury (DILI) secondary to acetaminophen, 2) DILI from other causes, 3) viral liver disease (hepatitis B virus, hepatitis A virus, hepatitis $C$ virus, varicella zoster virus, herpes simplex virus), 4) autoimmune liver disease (AIH), 5) Wilsons Disease, 6) Other (including Budd Chiari, hepatic artery thrombosis, ischemic cholangiopathy, rejection, primary graft nonfunction), and 7) unknown. Causative etiologies were defined based primary and secondary diagnosis codes as well as free text diagnosis fields.

The primary outcomes were LT and waitlist removal because of death or clinical deterioration. Other removal was also explored and included removal because of being too well and removal for other reasons including UNOS code 'other'. These outcomes were identified using UNOS waitlist removal codes. The secondary outcome was 1-year post LT survival.

This article is protected by copyright. All rights reserved. 


\section{Statistical Analysis}

Baseline characteristics are presented as percentages, means for normally distributed variables, and medians for non-normally distributed variables. Chi-squared tests were used to compare categorical variables and rank sum and t-tests used to compare continuous variables.

Absolute rates of LT were explored for the total cohort and by MELD quintile. Trends in waitlisting for Status-1 ALF patients were explored by comparing the percent change from 2002 to 2016 and by using a Spearman test for trend to explore the trend over the entire study period by race and ethnicity. Competing risk analysis was used to compare risk of waitlist removal because of LT or death/clinical deterioration. When differences in the primary outcome according to race/ethnicity were identified on univariable analysis, variables that were associated ( $p$ value $<0.10$ ) with the exposure and potentially associated with the outcome were added to the model to attempt to attenuate the disparity and explore the covariates contribution to the disparity. A full model that included all covariates was also explored.

Kaplan Meier survival analysis was used to explore racial differences 1-year survival. Survival curves were compared using log rank testing. All analyses were performed using STATA version 14 (STATA Corp, College Station, Texas).

\section{Results}

There were 151,317 adult patients who were black, white, Hispanic, or Asian waitlisted for LT during the study period. Of the 8,408 patients waitlisted with a diagnoses of ALF, 4,501 patients were waitlisted Status- 1 (55.3\% of whites, $64.4 \%$ of blacks, $51.6 \%$ of

This article is protected by copyright. All rights reserved. 
Hispanics, $40.7 \%$ of Asians, $p<0.001$ ). These 4,501 define the study cohort for the remainder of the analysis (Figure 1).

The majority of patients with ALF waitlisted Status-1 were women, with the highest proportion of women in the black cohort (61.2\% white, $70.2 \%$ black, $58.4 \%$ Hispanic, $52.0 \%$ Asian). Black patients with ALF waitlisted Status-1 had higher MELD score (36 black vs 34 white, 34 Hispanic, 35 Asian, p<0.001), INR (5.0 black vs 4.5 white, 4.3 Hispanic, 4.7 Asian, $\mathrm{p}=0.001)$, and bilirubin at waitlisting $(17.9 \mathrm{mg} / \mathrm{dl}$ black vs $11.3 \mathrm{mg} / \mathrm{dl}$ white, $16.0 \mathrm{mg} / \mathrm{dl}$ Hispanic, and $16.7 \mathrm{mg} / \mathrm{dl}$ Asian, $\mathrm{p}<0.001$ ) than other racial and ethnic groups (Table 1). There was no difference in the proportion of patients with grade 3 or 4 hepatic encephalopathy between the groups (Table 1). White patients were most likely to be on a ventilator at the time of waitlisting (Table 1). There was no significant difference in the number of patients waitlisted for a retransplant for any cause among the four groups $(3.4 \%$ white, $4.6 \%$ black, $2.7 \%$ Hispanic, $2.1 \%$ Asian, $p=0.14)$.

\section{Trends in ALF over time}

The numbers of ALF patients waitlisted Status- 1 has downtrended over the study period for all racial groups (Spearman: white -0.98, $p<0.001$; black $-0.89, p<0.001$, Hispanic 0.78, $\mathrm{p}<0.001$, Asian -0.76, $\mathrm{p}<0.001$ ) (Figure 2) (Supplemental table 1). Black patients continue to have the highest proportion of all registrants with ALF waitlisted Status-1 (white 1.2\%, Black 4.2\%, Hispanic 1.7\%, Asian 2.8\%).

\section{Etiologies of ALF}

The etiology of ALF in patients waitlisted Status-1 was most often unknown in all racial/ethnic groups (Table 1). DILI secondary to acetaminophen was most common in white patients (27.0\% white vs $10.5 \%$ black, $13.1 \%$ Hispanic, and $6.7 \%$ Asian, $p<0.001)$. Black patients were significantly more likely to have AlH as the etiology of their ALF than other groups (9.4\% blacks vs. $2.7 \%$ whites, $4.3 \%$ Hispanics, $2.7 \%$, and Asian, $p<0.001$ ). ALF

This article is protected by copyright. All rights reserved. 
secondary to viral etiologies was more common in Asian patients than other racial and ethnic groups (25.0\% Asian vs 5.2\% white, $10.6 \%$ black, and $8.4 \%$ Hispanic, $p<0.001)$ (Table 1 ).

\section{Waitlist removal because of $L T$ or death/clinical deterioration}

Of patients with ALF waitlisted Status-1 black patients were the most likely to be removed from the waitlist because of death or clinical deterioration ( $23.5 \%$ blacks vs $21.9 \%$ whites, $19.7 \%$ Hispanics, and $20.4 \%$ Asians; $p<0.001$ ). The median MELD at removal was highest in black patients (41 blacks vs 38 whites, 38 Hispanics, 39 Asians) (Table 2). The median time to death was 2 days for all racial and ethnic groups, with a interquartile range (IQR) between 0-4 days for all groups. On competing risk analysis (competing risk: LT), however there was no significant difference in waitlist removal because of death or clinical deterioration between black and white patients (HR 1.04; 95\% Cl 0.89-1.21)(Table 3).

Of patients with ALF waitlisted Status-1 black patients were the most likely to undergo LT (black $62.0 \%$, vs 53.0\% whites, 59.5\% Hispanics, 59.8\% Asians, $p<0.001$ ). The median MELD at LT was 35 for black patients and 34 for other racial and ethnic groups $(p=0.06)$ (Table 2). The median time to LT was 2 days for all groups with an IQR between 14 days for all groups. On competing risk analysis (competing risk: waitlist removal because of death or clinical deterioration) black patients were significantly more likely to undergo LT (HR 1.20; 95\% Cl 1.08-1.30) than white patients (Table 3). On multivariable analysis serum bilirubin (HR 1.04; 95\% Cl 0.94-1.14) as well as a full model which included age, BMI, blood type, gender, diabetes, bilirubin, INR, creatinine, causative etiology, grade 3-4 encephalopathy, ventilator use, dialysis, and region explained the difference in LT (HR 1.00, 95\% Cl 0.91-1.11) (Table 4).

This article is protected by copyright. All rights reserved. 
We performed a separate analysis that excluded retransplant patients. There remained no racial/ethnic difference in waitlist removal because of death or clinical deterioration and black patients continued to be more likely than white patients to undergo LT.

Eighty-nine percent of patients who were removed from the waitlist because of reasons other than LT or clinical deterioration/death were removed because of clinical improvement. Black patients were the least likely to be removed from the waitlist for reasons other than death/clinical deterioration or LT (13.8\% black, $24.8 \%$ white, $20.9 \%$ Hispanics, and $19.5 \%$ Asian, $\mathrm{p}<0.001$ ) (Table 2).

\section{Post-transplant survival}

Seventy-nine percent of the deaths that occurred (366/463) in the first year after LT occurred in the first 90 days. While black patients had the lowest 90-day survival this difference was not significant (83.3\% black vs $85.5 \%$ whites, $85.9 \%$ Hispanics, $91.4 \%$ Asians, $\mathrm{p}=0.09$ ). Black patients had significantly lower 1 -year post transplant survival than other groups (79.6\% blacks vs $82.8 \%$ whites, $83.9 \%$ Hispanics, $89.3 \%$ Asians, $p=0.02)$ (Figure 3). This remained true when retransplant patients were excluded from the analysis (78.0\% blacks vs $81.6 \%$ whites, $83.1 \%$ Hispanics, $88.9 \%$ in Asians, $p=0.01$ ).

\section{Discussion}

ALF prognosis depends on the underlying causative etiology, age, duration of time over which the disease develops, the extent of the liver damage, and early institution of supportive care ${ }^{10}$. It has not been clear how these prognostic factors vary by race or ethnicity. Here we demonstrate that the etiology of ALF in those adult patients that require Status- 1 waitlisting varies by race and ethnicity. We further demonstrate that black patients This article is protected by copyright. All rights reserved. 
waitlisted with ALF are sicker on presentation than other groups and are more often waitlisted Status-1. This acuity lead to higher rates of LT in black patients compared to white patients, sparing black patients from higher rates of waitlist removal due to death or clinical deterioration. Black patients had the lowest 1-year post transplant survival in the cohort.

The underlying cause of ALF is known to impact prognosis. In a prospective study patients with acetaminophen overdose, hepatitis $A$, ischemic hepatitis, or pregnancy related ALF, survival without LT was greater than $50 \%$ compared to patient with ALF from indeterminate causes, non-acetaminophen overdose, hepatitis B virus, autoimmune hepatitis, Wilson disease, or Budd Chiari syndrome who had short-term transplant free survival of less than $25 \%^{11,12}$. In our cohort, Hispanic and black patients were the most likely to have unknown causes of their ALF and black patients were also most to have AlH as a causative etiology. It is possible that these underlying poor prognosis etiologies contributed to the higher rates of Status-1 waitlisting and LT for black patients.

In our study black patients had higher MELD scores, INR, and bilirubin on presentation than white patients. Black patients with chronic liver disease have been shown to be sicker at waitlisting, with higher MELD scores than white patients ${ }^{8}$. In a report from the ALF Study Group, black patients had similar MELD scores to white and Asian patients on presentation (blacks 33.9, whites 32.7 , Asians 33.0; $p=0.42$ ), however they did have higher bilirubin than white patients (black $18.3 \mathrm{mg} / \mathrm{dl}$ vs $6.6 \mathrm{mg} / \mathrm{dl}$ whites) ${ }^{2}$. The higher bilirubin in black patients may reflect the differences in underlying causative etiology. DILI, which is most often acetaminophen, presents with transaminitis while viral and unknown causes are more likely to have a component of cholestasis ${ }^{13}$. The higher bilirubin and resultant higher MELD score likely drove the differences in Status- 1 waitlisting and therefore LT between white and black patients.

This article is protected by copyright. All rights reserved. 
Black patients with ALF waitlisted Status-1 were more likely to undergo LT than white patients. In the ALF Group database study, there was no difference in LT between black and white patients and higher rates of LT in Hispanic patients ${ }^{2}$. In this cohort however not all patients were waitlisted for $\mathrm{LT}$, therefore this likely represented a less critically ill population than our cohort. On multivariable analysis demographic, clinical, and allocation factors were able to fully explained (HR 1.20 $\rightarrow$ HR 1.00) the difference in LT between black and whites, suggesting that these covariates contribute to the differences in LT between blacks in white patients waitlisted Status- 1 for LT.

It might have been expected that black patients would have higher rates of waitlist removal given their sicker presentation compared to white patients. However, the competing risk analysis suggest that LT was protective against waitlist removal. White patients had the highest rates of other removal which is predominately removal for clinical improvement. It is unclear if this is because of higher rates of acetaminophen DILI which has better prognosis, or reflects more aggressive evaluation and listing practices in this group.

Black patients with ALF waitlisted Status-1 for LT had lower 1-year post transplant survival than other groups while Asian patients had the highest 1-year post transplant survival. Similar trends have been seen in chronic liver disease with lower 2-year and 5-year post transplant survival in black, patients ${ }^{14,15}$. The reasons for these disparities are unclear. In chronic liver disease hypothesis include differences in recipient underlying health status, liver donor quality, and rejection ${ }^{16}$.

This study is the first to explore causative etiologies and outcomes in a large cohort of black, Hispanic, and Asian patients with ALF waitlisted for LT. This study has several potential limitations. First, much of the data on causative etiologies depend on free text entered into the UNOS database. As such, patients in our cohort were classified as having an unknown cause of ALF at higher rates than prospective studies of ALF. It is possible that there were misclassifications, however causative etiologies were unlikely to be coded

This article is protected by copyright. All rights reserved. 
differently by race/ethnicity. Second, we do not have explants histology or imaging to explore the potential hypothesis of acute on chronic liver disease in this cohort. It is possible that black patients had a component of underlying chronic liver disease that lead to more acute presentation. This potential bias lead us to focus on an ALF cohort that was waitlisted Status- 1 therefore requiring the waitlisting physician to more thoroughly investigate the potential for underlying chronic liver disease. We included all patients with a diagnosis code of ALF and Status-1 waitlisting therefor some primary graft non-function patients and hepatic artery thrombosis patients were included. However, when we excluded all re-transplants this did not change the univariable, multivariable, or post- transplant analysis. It is unclear why $55 \%$ of registrants carried a diagnosis of ALF but were not waitlisted Status-1. Again, this may have been due to acute on chronic liver failure, leading us to focus on those patients waitlisted Status-1 and most likely to have true ALF. Finally, we do not have information on the time from first identification of ALF and presentation to a LT center. It is possible that delays in care lead to more severe liver disease on presentation in black patients compared to other racial groups and higher rates of LT. However it is notable that this was not seen in the Hispanic cohort who might be hypothesized to have similar issues with access to care.

In summary, this is the first study to explore prognostic factors including age, gender, causative disease etiology, as well as outcomes in a large cohort of diverse adult patients waitlisted for LT. Causative etiologies of ALF in those patients waitlisted Status- 1 vary by race and ethnicity. Furthermore, black patients are sicker on presentation and more frequently require LT for ALF. Finally, black patients have lower 1-year post-transplant survival than other racial/ethnic groups. Additional prospective studies are needed to determine if worse disease on presentation is related to late presentation or referral, acute on chronic liver disease, or inherently worse ALF.

This article is protected by copyright. All rights reserved. 


\section{References}

1. Bernal W, Wendon J. Acute liver failure. The New England journal of medicine. 2013;369(26):2525-2534.

2. Forde KA, Reddy KR, Troxel AB, Sanders $C M$, Lee WM. Racial and ethnic differences in presentation, etiology, and outcomes of acute liver failure in the United States. Clinical gastroenterology and hepatology : the official clinical practice journal of the American Gastroenterological Association. 2009;7(10):1121-1126.

3. Lee WM, Squires RH, Jr., Nyberg SL, Doo E, Hoofnagle JH. Acute liver failure: Summary of a workshop. Hepatology. 2008;47(4):1401-1415.

4. Nguyen GC, Thuluvath PJ. Racial disparity in liver disease: Biological, cultural, or socioeconomic factors. Hepatology (Baltimore, Md). 2008;47(3):1058-1066.

5. Kanwal F, Kramer JR, El-Serag HB, et al. Race and Gender Differences in the Use of Direct Acting Antiviral Agents for Hepatitis C Virus. Clinical infectious diseases : an official publication of the Infectious Diseases Society of America. 2016;63(3):291-299.

6. Nguyen GC, Segev DL, Thuluvath PJ. Racial disparities in the management of hospitalized patients with cirrhosis and complications of portal hypertension: a national study. Hepatology. 2007;45(5):1282-1289.

7. Reid AE, Resnick M, Chang Y, Buerstatte N, Weissman JS. Disparity in use of orthotopic liver transplantation among blacks and whites. Liver transplantation : official publication of the American Association for the Study of Liver Diseases and the International Liver Transplantation Society. 2004;10(7):834-841.

8. Moylan CA, Brady CW, Johnson JL, Smith AD, Tuttle-Newhall JE, Muir AJ. Disparities in liver transplantation before and after introduction of the MELD score. Jama. 2008;300(20):23712378.

9. Washburn K, Harper A, Klintmalm G, Goss J, Halff G. Regional sharing for adult status 1 candidates: reduction in waitlist mortality. Liver transplantation : official publication of the American Association for the Study of Liver Diseases and the International Liver Transplantation Society. 2006;12(3):470-474.

10. Marudanayagam R, Shanmugam V, Gunson B, et al. Aetiology and outcome of acute liver failure. HPB (Oxford). 2009;11(5):429-434.

11. Ostapowicz G, Fontana RJ, Schiodt FV, et al. Results of a prospective study of acute liver failure at 17 tertiary care centers in the United States. Ann Intern Med. 2002;137(12):947954.

12. Castaldo ET, Chari RS. Liver transplantation for acute hepatic failure. HPB (Oxford). 2006;8(1):29-34.

This article is protected by copyright. All rights reserved. 
13. Fontana RJ. Acute liver failure including acetaminophen overdose. Med Clin North Am. 2008;92(4):761-794, viii.

14. Thuluvath PJ, Guidinger MK, Fung JJ, Johnson LB, Rayhill SC, Pelletier SJ. Liver transplantation in the United States, 1999-2008. American journal of transplantation : official journal of the American Society of Transplantation and the American Society of Transplant Surgeons. 2010;10(4 Pt 2):1003-1019.

15. Ananthakrishnan AN, Saeian K. Racial differences in liver transplantation outcomes in the MELD era. Am J Gastroenterol. 2008;103(4):901-910.

16. Mathur AK, Schaubel DE, Zhang H, Guidinger MK, Merion RM. Disparities in liver transplantation: the association between donor quality and recipient race/ethnicity and sex. Transplantation. 2014;97(8):862-869.

This article is protected by copyright. All rights reserved. 
Table 1. Clinical characteristics of adult patients with acute liver failure waitlisted status-1 for liver transplantation.

\begin{tabular}{|c|c|c|c|c|c|}
\hline & $\begin{array}{c}\text { White } \\
n=2,876\end{array}$ & $\begin{array}{l}\text { Black } \\
n=790\end{array}$ & $\begin{array}{c}\text { Hispanic } \\
n=513\end{array}$ & $\begin{array}{l}\text { Asian } \\
n=328\end{array}$ & $P$ value \\
\hline $\begin{array}{l}\text { Age (years) } \\
\text { (mean, SD) }\end{array}$ & $34.2 \pm 9.4$ & $36.3 \pm 9.0$ & $34.4 \pm 9.0$ & $34.8 \pm 9.0$ & $<0.001$ \\
\hline Female (\%) & $61.2 \%$ & $70.2 \%$ & $58.4 \%$ & $52.0 \%$ & $<0.001$ \\
\hline BMI (mean, SD) & $27.2(6.1)$ & $29.7(7.4)$ & $28.8(6.4)$ & $25.1(4.6)$ & $<0.001$ \\
\hline Diabetes (\%) & $8.5 \%$ & $9.1 \%$ & $12.8 \%$ & $11.0 \%$ & 0.03 \\
\hline Blood type $O(\%)$ & $46.0 \%$ & $50.6 \%$ & $58.1 \%$ & $33.3 \%$ & $<0.001$ \\
\hline Etiology of ALF & & & & & $<0.001$ \\
\hline Acetaminophen & $27.0 \%$ & $10.5 \%$ & $13.1 \%$ & $6.7 \%$ & \\
\hline DILI & $6.8 \%$ & $10.3 \%$ & $9.2 \%$ & $10.4 \%$ & \\
\hline Viral & $5.3 \%$ & $10.4 \%$ & $8.4 \%$ & $25.0 \%$ & \\
\hline AlH & $2.7 \%$ & $9.4 \%$ & $4.3 \%$ & $2.7 \%$ & \\
\hline Wilsons & $0.6 \%$ & $0.1 \%$ & $1.0 \%$ & $0.6 \%$ & \\
\hline Unknown & $34.7 \%$ & $42.8 \%$ & $43.7 \%$ & $37.8 \%$ & \\
\hline $\begin{array}{l}\text { MELD } \\
\text { (median, IQ } \\
\text { range) }\end{array}$ & $\begin{array}{c}34 \\
(28-41)\end{array}$ & $\begin{array}{c}36 \\
(30-42)\end{array}$ & $\begin{array}{c}34 \\
(29-39)\end{array}$ & $\begin{array}{c}35 \\
(29-41)\end{array}$ & $<0.001$ \\
\hline INR (mean, SD) & $4.5 \pm 4.3$ & $5.0 \pm 6.8$ & $4.3 \pm 3.7$ & $4.7 \pm 6.0$ & 0.08 \\
\hline
\end{tabular}

This article is protected by copyright. All rights reserved. 


\begin{tabular}{|l|l|l|l|l|l|}
\hline $\begin{array}{l}\text { Creatinine (mg/dl) } \\
\text { (mean, SD) }\end{array}$ & $2.1 \pm 1.6$ & $1.9 \pm 1.6$ & $1.8 \pm 1.6$ & $1.6 \pm 1.5$ & $<0.001$ \\
\hline Bilirubin (mg/dl) & $11.3 \pm 10.5$ & $17.9 \pm 11.1$ & $16.0 \pm 11.4$ & $16.7 \pm 11.3$ & $<0.001$ \\
(mean, SD) & & 63.2 & 58.7 & 55.5 & 0.09 \\
\hline Grade 3-4 HE (\%) & 60.0 & $46.2 \%$ & $49.7 \%$ & $42.4 \%$ & $<0.001$ \\
\hline Ventilator (\%) & $53.5 \%$ & $11.1 \%$ & $13.1 \%$ & $11.3 \%$ & 0.75 \\
\hline Dialysis (\%) & $12.8 \%$ & & & & \\
\hline
\end{tabular}

Abbreviations: Acute liver failure (ALF), model for end stage liver disease score (MELD), international normalized ration (INR), hepatic encephalopathy (HE). 
Table 2. Waitlist removal in adult patients with acute liver failure waitlisted status-1 for liver transplantation, by race/ethnicity.

\begin{tabular}{|c|c|c|c|c|c|}
\hline & $\begin{array}{c}\text { White } \\
\mathrm{n}=2,876\end{array}$ & $\begin{array}{l}\text { Black } \\
n=790\end{array}$ & $\begin{array}{c}\text { Hispanic } \\
n=513\end{array}$ & $\begin{array}{l}\text { Asian } \\
n=328\end{array}$ & $P$ value \\
\hline $\begin{array}{l}\text { Death or clinical } \\
\text { deterioration }\end{array}$ & $\begin{array}{c}630 \\
(21.9)\end{array}$ & $\begin{array}{c}186 \\
(23.5)\end{array}$ & $\begin{array}{c}101 \\
(19.7)\end{array}$ & $\begin{array}{c}67 \\
(20.4)\end{array}$ & $<0.001$ \\
\hline $\begin{array}{l}\text { Removal MELD } \\
\text { (median, IQ range) }\end{array}$ & $\begin{array}{c}38 \\
(31-44)\end{array}$ & $\begin{array}{c}41 \\
(13-75)\end{array}$ & $\begin{array}{c}38 \\
(31-44)\end{array}$ & $\begin{array}{c}39 \\
(31-46)\end{array}$ & 0.01 \\
\hline Transplanted & $\begin{array}{l}1,524 \\
(53.0)\end{array}$ & $\begin{array}{c}490 \\
(62.0)\end{array}$ & $\begin{array}{c}305 \\
(59.5)\end{array}$ & $\begin{array}{c}196 \\
(59.8)\end{array}$ & $<0.001$ \\
\hline $\begin{array}{l}\text { Transplant MELD } \\
\text { (median, IQ range) }\end{array}$ & $\begin{array}{c}34 \\
(27-40)\end{array}$ & $\begin{array}{c}35 \\
(30-40)\end{array}$ & $\begin{array}{c}34 \\
(28-39)\end{array}$ & $\begin{array}{c}34 \\
(28-41)\end{array}$ & 0.06 \\
\hline Other removal* & $\begin{array}{c}713 \\
(24.8)\end{array}$ & $\begin{array}{c}114 \\
(13.8)\end{array}$ & $\begin{array}{c}107 \\
(20.9)\end{array}$ & $\begin{array}{c}64 \\
(19.5)\end{array}$ & $<0.001$ \\
\hline $\begin{array}{l}\text { Remained on } \\
\text { waitlist }\end{array}$ & $\begin{array}{c}9 \\
(0.5)\end{array}$ & $\begin{array}{l}0 \\
(0)\end{array}$ & $\begin{array}{l}0 \\
(0)\end{array}$ & $\begin{array}{c}1 \\
(0.3)\end{array}$ & 0.25 \\
\hline
\end{tabular}

Abbreviations: model for end stage liver disease score (MELD)

*Eighty-nine percent of other removals were defined as being removed because of clinical improvement.

This article is protected by copyright. All rights reserved. 
Table 3. Competing risk analysis: liver transplantation and waitlist removal because of death or clinical deterioration, by race/ethnicity

\begin{tabular}{|c|l|}
\hline & \multicolumn{1}{|c|}{ Unadjusted HR } \\
& \multicolumn{1}{|c|}{$(95 \% \mathrm{Cl})$} \\
\hline Death or Clinical Deterioration & \\
\hline White & Reference \\
\hline Black & HR $1.04(\mathrm{Cl} 0.89-1.21)$ \\
\hline Hispanic & HR 0.87 (0.71-1.08) \\
\hline Asian & HR 0.88 (0.69-1.13) \\
\hline Transplanted & Reference \\
\hline White & HR 1.20 (Cl 1.08-1.30) \\
\hline Black & HR $1.11(1.00-1.25)$ \\
\hline Hispanic & HR 1.13 (0.98-1.3) \\
\hline Asian &
\end{tabular}

Abbreviations: Hazard ration (HR)

This article is protected by copyright. All rights reserved. 
Table 4. Competing risk multivariable analysis: liver transplantation in black compared to white adult patients

\begin{tabular}{|c|c|}
\hline & HR (95\% Cl) \\
\hline Unadjusted & $1.20(1.081 .30)$ \\
\hline \multicolumn{2}{|c|}{ Adjusted for single variable } \\
\hline Age & $1.20(1.09-1.32)$ \\
\hline BMI & $1.15(1.04-1.27)$ \\
\hline Diabetes & $1.20(1.09-1.32)$ \\
\hline Blood type & $1.20(1.10-1.33)$ \\
\hline Gender & $1.19(1.09-1.32)$ \\
\hline Bilirubin & $1.04(0.94-1.14)$ \\
\hline INR & $1.19(1.08-1.30)$ \\
\hline Creatinine & $1.18(1.07-1.30)$ \\
\hline MELD & $1.18(1.08-1.30)$ \\
\hline Etiology & $1.09(1.00-1.20)$ \\
\hline Grade 3-4 HE & $1.19(1.09-1.31)$ \\
\hline Ventilator & $1.18(1.08-1.30)$ \\
\hline Dialysis & $1.19(1.08-1.30)$ \\
\hline Region & $1.14(1.04-1.25)$ \\
\hline \multicolumn{2}{|l|}{ Full model ${ }^{*}$} \\
\hline & $1.00(0.91-1.11)$ \\
\hline
\end{tabular}

Abbreviations: Hazard ration (HR), model for end stage liver disease score (MELD), international normalized ration (INR)

*includes all variables in table except MELD. Variables are categorized as presented in Table 1

This article is protected by copyright. All rights reserved. 
Figure 1. Consort Diagram: Adult patients waitlisted for liver transplantation with acute liver failure and ultimately waitlisted status-1
A. All patient waitlisted for LT and the denominator of Figure $2 \mathrm{~B}$. Patients with diagnosis code for ALF C Patients with a diagnosis code for ALF and waitlisted Status-1, the numerator for Figure 2, and they study cohort

Figure 2. Trends in acute liver failure in adult patients waitlisted status 1 from 2002-2016 in patients by race/ethnicity.

Abbreviations: Acute Liver Failure (ALF)

Figure 3. Kaplan-Meier 1-year post liver transplant survival

This article is protected by copyright. All rights reserved. 


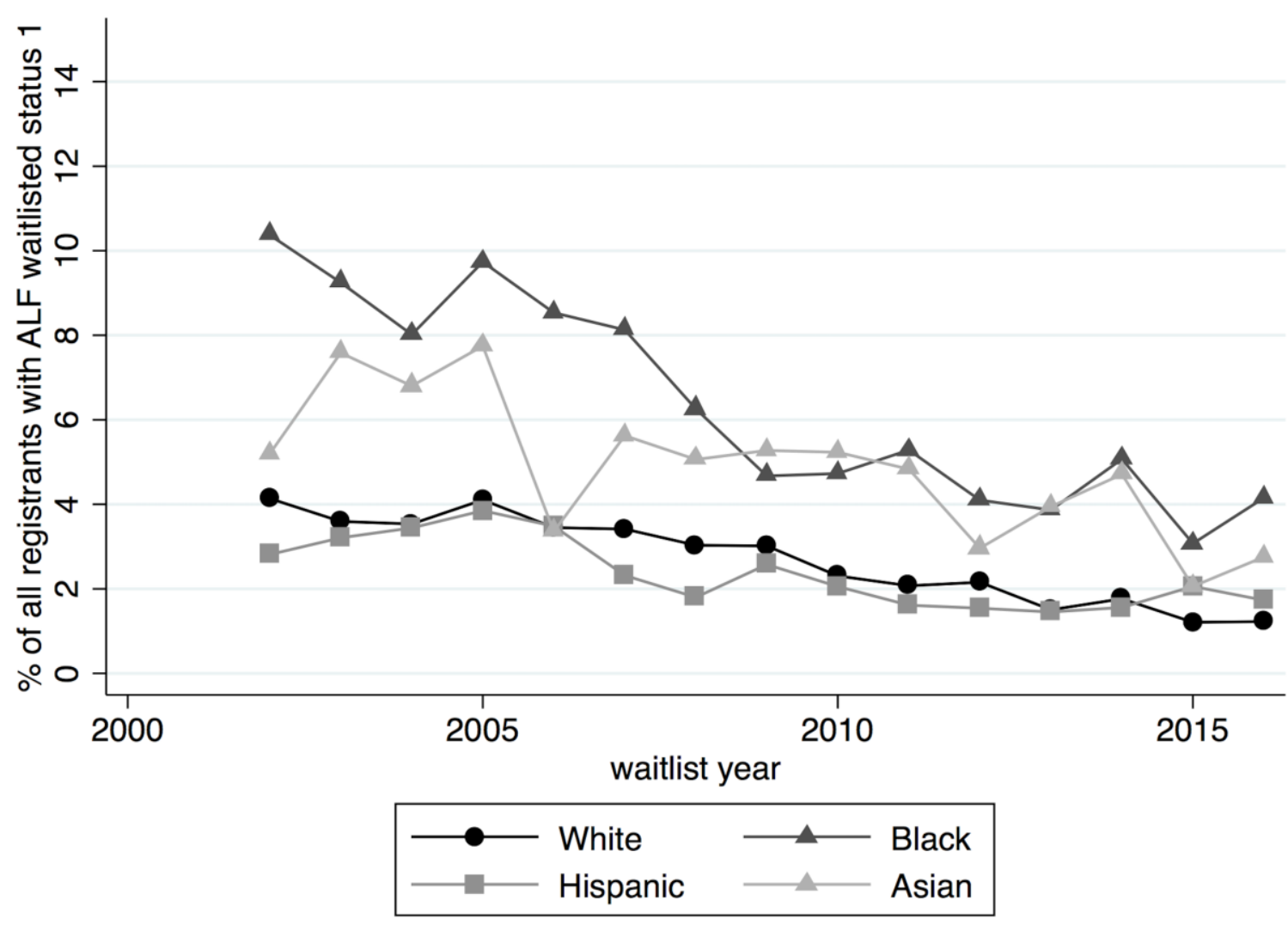

This article is protected by copyright. All rights reserved. 


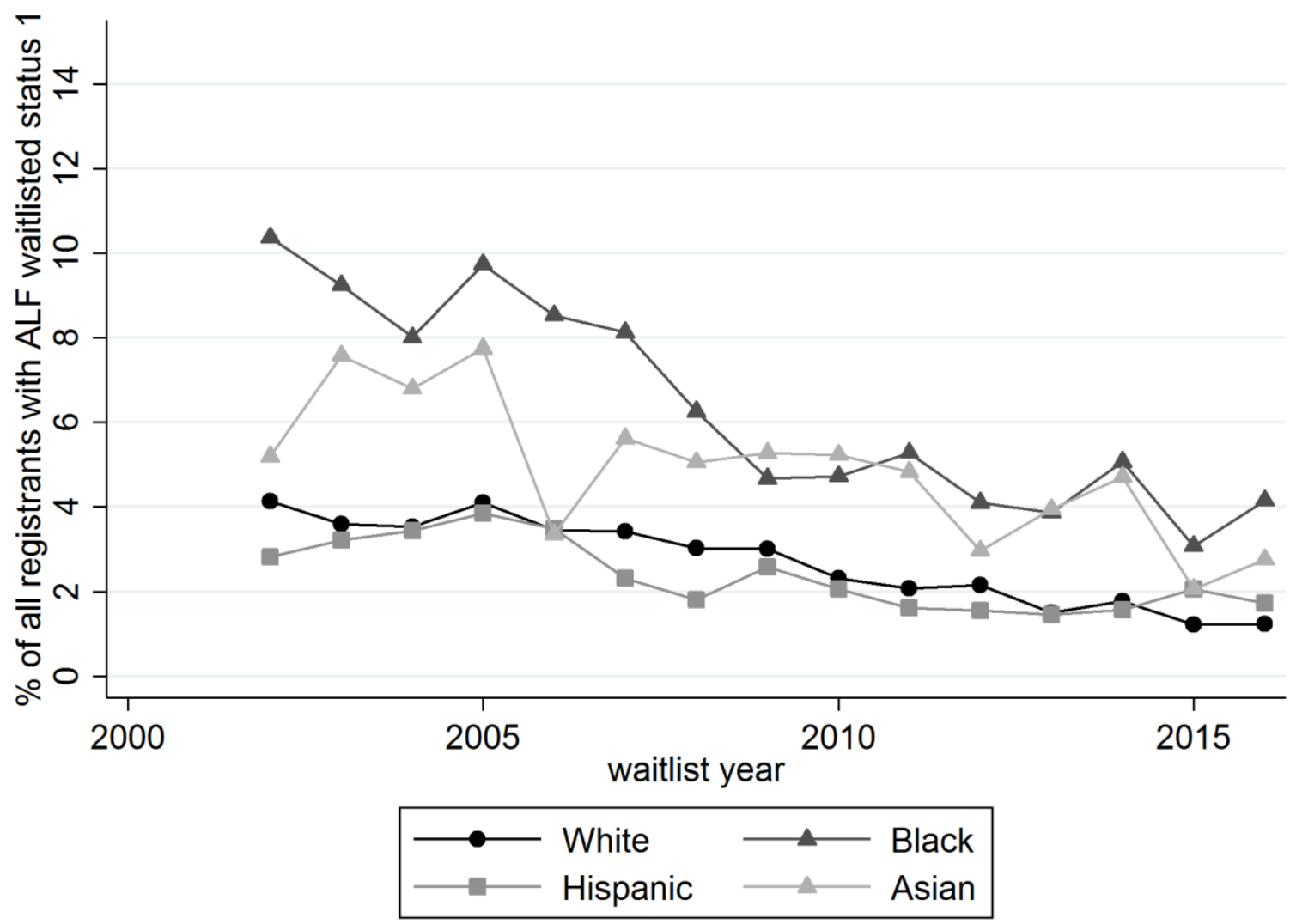

This article is protected by copyright. All rights reserved. 


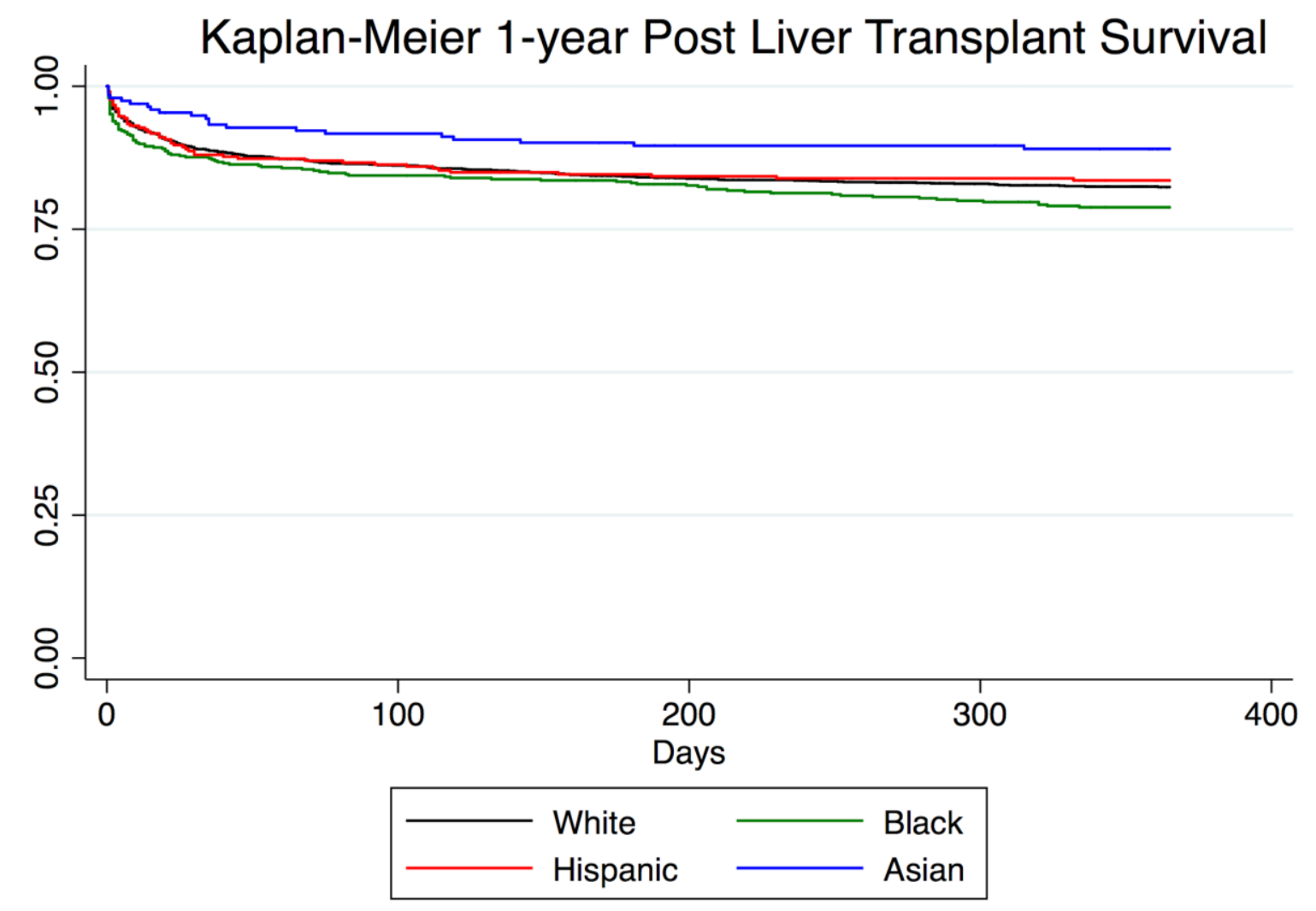

This article is protected by copyright. All rights reserved. 